\title{
Article
}

\section{The RNA-Binding Protein ESRP1 Modulates the Expression of RAC1b in Colorectal Cancer Cells}

\author{
Marta Manco ${ }^{1,+}$, Ugo Ala ${ }^{2,+}{ }^{(D)}$, Daniela Cantarella ${ }^{3}$, Emanuela Tolosano ${ }^{1}\left(\mathbb{D}\right.$, Enzo Medico $^{3} \mathbb{C D}_{\text {, }}$ \\ Fiorella Altruda $2, *$ (D) and Sharmila Fagoonee $4, *$ (D)
}

1 Molecular Biotechnology Center, Department of Molecular Biotechnology and Health Sciences, University of Turin, 10126 Turin, Italy; marta.manco@unito.it (M.M.); emanuela.tolosano@unito.it (E.T.)

2 Department of Veterinary Science, University of Turin, Largo Paolo Braccini 2, 10095 Grugliasco, Italy; ugo.ala@unito.it

3 Department of Oncology, University of Torino, S.P. 142, km 3.95, Torino, 10060 Candiolo, Italy; daniela.cantarella@ircc.it (D.C.); enzo.medico@ircc.it (E.M.)

4 Institute of Biostructure and Bioimaging, National Research Council (CNR) c/o Molecular Biotechnology Center, 10126 Turin, Italy

* Correspondence: fiorella.altruda@unito.it (F.A.); sharmila.fagoonee@unito.it or sharmila.fagoonee@cnr.it (S.F.)

+ These authors contributed equally to this work.

Citation: Manco, M.; Ala, U.; Cantarella, D.; Tolosano, E.; Medico, E.; Altruda, F.; Fagoonee, S. The RNA-Binding Protein ESRP1 Modulates the Expression of RAC1b in Colorectal Cancer Cells. Cancers 2021, 13, 4092. https://doi.org/ 10.3390/cancers13164092

Academic Editor: John Souglakos

Received: 29 June 2021

Accepted: 9 August 2021

Published: 13 August 2021

Publisher's Note: MDPI stays neutral with regard to jurisdictional claims in published maps and institutional affiliations.

Copyright: (C) 2021 by the authors Licensee MDPI, Basel, Switzerland. This article is an open access article distributed under the terms and conditions of the Creative Commons Attribution (CC BY) license (https:// creativecommons.org/licenses/by/ $4.0 /)$.
Simple Summary: Colorectal cancer (CRC) ranks third for incidence and second for number of deaths among cancer types worldwide. Poor patient survival due to inadequate response to currently available treatment regimens points to the urgent requirement for personalized therapy in CRC patients. Our aim was to provide mechanistic insights into the pro-tumorigenic role of the RNAbinding protein ESRP1, which is highly expressed in a subset of CRC patients. We show that, in CRC cells, ESRP1 binds to and has the same trend in expression as RAC1b, a well-known tumor promoter. Thus, RAC1b may be a potential therapeutic target in ESRP1-overexpressing CRC.

Abstract: RNA binding proteins are well recognized as critical regulators of tumorigenic processes through their capacity to modulate RNA biogenesis, including alternative splicing, RNA stability and mRNA translation. The RNA binding protein Epithelial Splicing Regulatory Protein 1 (ESRP1) can act as a tumor suppressor or promoter in a cell type- and disease context-dependent manner. We have previously shown that elevated expression of ESRP1 in colorectal cancer cells can drive tumor progression. To gain further insights into the pro-tumorigenic mechanism of action of ESRP1, we performed cDNA microarray analysis on two colorectal cells lines modulated for ESRP1 expression. Intriguingly, RAC1b was highly expressed, both at mRNA and protein levels, in ESRP1-overexpressing cells, while the opposite trend was observed in ESRP1-silenced CRC cells. Moreover, RAC1 and RAC1b mRNA co-immunoprecipitate with ESRP1 protein. Silencing of RAC1b expression significantly reduced the number of soft agar colonies formed by ESRP1-overexpressing cells, suggesting that ESRP1 acted, at least partially, through $R A C 1 b$ in its tumor-promoting activities in CRC cells. Thus, our data provide molecular cues on targetable candidates in CRC cases with high ESRP1 expression.

Keywords: colorectal cancer; ESRP1; RNA-binding protein; RAC1; RAC1b; alternative splicing; cDNA microarray; bioinformatics analysis

\section{Introduction}

Colorectal cancer (CRC) ranks third for prevalence and second for number of deaths among all cancers worldwide [1]. According to the worldwide cancer burden in 2020 and GLOBOCAN estimates of cancer incidence and mortality produced by the International Agency for Research on Cancer, CRC was fifth among cancers with newly diagnosed cases, as well as deaths in 2020 [1]. Management of this malignant tumor is achieved by several strategies, including chemotherapy and targeted therapy using small molecules [2]. 
However, poor patient survival, due to inadequate response to currently available treatment regimens and shortage of adequate risk-assessment biomarkers, points out to the urgent requirement for personalized therapy in CRC patients.

In an era of human genomic, transcriptomic and proteomic exploration of human pathologies through high throughput technologies, dissecting the molecular pathways involved in oncogenic processes to design new patient-tailored therapies has become feasible. Several biomolecules work in concert to initiate and promote tumorigenesis. The crucial role of several oncogenic and tumor suppressor transcription factors in CRC initiation and progression have been reported. For instance, the epithelial to mesenchymal transition (EMT)-regulators zinc finger E-box- binding homeobox-(ZEB)-1 and -2, snail family transcriptional repressor 2 (SLUG), snail family transcriptional repressor 1 (SNAI1) and TWIST-related protein 1 (TWIST) are critical drivers of tumor progression [3,4]. Epigenetic changes such as DNA methylation and histone modifications are implicated in several CRC-associated pathways [5]. Non-coding RNAs, including long non-coding RNAs and microRNAs, exert regulatory functions in the multistep processes of carcinogenesis [6-8]. RNA binding proteins (RBPs) have also surged as essential modulators in every cancer hallmark, both as tumor promoters and suppressors, as well as regulators of genetic stability. Recently, an integrated analysis of RBPs in human CRC was performed by Fan et al. [9]. The authors identified 12 prognostic RBPs, which were modulated in CRC and warrant in-depth studies. RBPs have pleiotropic activities in RNA processing and metabolism, such as alternative splicing and translation. They can interact with proteins and different types of RNA species to generate ribonuclear protein complexes with different combinations in a context- and disease-specific manner, thus putting RBPs and related pathways at the forefront of cancer therapeutics development [10].

Aberrant expression of RBPs influences cancer-related cellular phenotypes. We have previously shown that the overexpression of Epithelial Splicing Regulatory Protein 1 (ESRP1) can promote cancer traits in CRC cells, by increasing their anchorage-independency and enhancing their clonogenic capacity in vitro, as well as promoting macrometastasis formation in vivo [11]. Autocrine activation of fibroblast growth factor receptor (FGFR2IIIb, a splicing target of ESRP1) played an important part in these phenotypes. There was marked PI3K/AKT pathway activation and SNAI1 protein overexpression, which skewed the cells towards adopting a partially mesenchymal, and more tumorigenic, molecular profile. These data were further supported by proteomics data on ESRP1-modulated CRC cells [12]. The observation that ESRP1 can have pro-tumorigenic and pro-metastatic activities was also shown by other studies [13-15]. Leontieva et al. demonstrated that ESRP1 could exert differential effects on protein translation of oncogenic mRNAs, such as MYC and FOS, according to the complexity of their $5^{\prime}$ UTR secondary structure [15]. Yae et al. reported that ESRP1 promotes the splicing of CD44v isoform, which stabilizes the cysteine transporter $\mathrm{xCT}$ and promotes the synthesis of reduced glutathione (GSH) to enhance the ROS resistance of metastatic cancer cells [13]. ESRP1 expression status of melanomas played a significant role on cytolytic activity and in influencing survival of patients (ESRP1-low patients had better outcome) [16]. Jeong et al. also showed that high ESRP1 expression significantly negatively correlated with five-year survival of ovarian cancer patients [14]. Moreover, Lee et al. reported that the higher ESRP1 expression represented an unfavorable prognostic factor in prostate cancer, and increased the risk of disease progression and cancer-specific death in this disease [17].

The expression ESRP1 and its paralog ESRP2 is highly plastic, and several up-regulation and down-regulation episodes are seen in the multistep process of cancer progression, pointing out the difficulty in designing therapeutics against these molecules [18]. It is thus crucial to fully dissect the molecular events regulated by ESRP1 in CRC in order to appropriately target tumor progression. To gain further insights into the mechanism by which ESRP1 exerts a pro-tumorigenic activity in CRC cells, we performed a high throughput cDNA microarray on two cell lines, COLO320DM and HCA24, modulated for 
ESRP1 expression. Intriguingly, our data show, unprecedently that ESRP1 promotes the expression of and involves RAC1b in its cancer-promoting role.

\section{Materials and Methods}

\subsection{Cell Lines and ESRP1 Expression Modulation}

The CRC cell lines used in this study had been previously characterized, at both the genomic and transcriptomic level, and authenticated [19]. COLO320DM cells were cultured in RPMI (ThermoFisher Scientific, Monza, Italy), 10\% FBS and penicillin/streptomycin (PS), while HCA24 and Caco-2 cells were kept in DMEM, 10\% FBS and PS as previously described [12]. ESRP1 expression was modulated with shRNA cloned into pLKO.1 lentiviral vector for stable knockdown and with human ESRP1 ORF cloned into pLX304 lentiviral vector for stable overexpression [11]. RAC1b expression was transiently reduced by using siRNA against this gene by using lipofectamine as described (Table S1) [20].

\subsection{RNA Extraction and Quantitative Real-Time PCR}

RNA was extracted using the PureLink RNA kit (ThermoFisher Scientific, Monza, Italy) and cDNA prepared with the High-capacity cDNA Reverse Transcription kit (ThermoFisher Scientific, Monza, Italy). Real-time PCR (qRT-PCR) was performed to analyze target gene expression as previously described $[11,21]$. Gene expression was normalized to endogenous $18 \mathrm{~s}$ (for Taqman gene expression assays) or GAPDH expression. Primer sequences are reported in Table S1 [22-31].

\section{3. cDNA Microarray Analysis}

Gene expression profiling was performed as previously described [11]. Briefly, RNA was extracted using miRNeasy Mini Kit (Qiagen, Milano, Italy), according to the manufacturer's protocol. RNA quantification, quality assessment, cRNA synthesis, hybridization and data processing are described in the Supplementary Materials. COLO320DM cells overexpressing ESRP1 and ESRP1-silenced HCA24 cells were compared to empty and scramble controls, respectively. Bioconductor limma package was used for differential expression analysis with Benjamini-Hochberg (BH) method for False Discovery Rate (FDR) evaluation [32]. For the COLO320DM data, cut-off values were set to $p$-value adj $<0.05$ and $\operatorname{abs}\left(\log _{2} \mathrm{FC}\right)>\log _{2}(1.5)$ whereas for HCA24 $p$-value adj $<0.01$ and abs $\left(\log _{2}\right.$ FC) $>\log _{2}(1.5)$, in order to limit the number of differentially expressed genes. Datasets have been deposited in the GEO repository (GSE180125 and GSE180126).

\subsection{RNA-Immunoprecipitation}

RNA immunoprecipitation was performed as previously described [12]. Briefly, total cell protein extracts were obtained by incubating COLO320DM cells overexpressing ESRP1 for $5 \mathrm{~min}$ in cold isotonic buffer ( $20 \mathrm{mM}$ HEPES, $100 \mathrm{mM} \mathrm{NaCl}, 250 \mathrm{mM}$ Sucrose, $5 \mathrm{mM} \mathrm{MgCl}_{2}$ ), a cocktail of protease inhibitors (Roche, Milan, Italy) and RNAse inhibitor (Promega, Milan, Italy) and DTT. The lysates were precleared for $1 \mathrm{~h}$ at $4{ }^{\circ} \mathrm{C}$ using Dynabeads protein G. Anti-ESRP1 antibody (Sigma-Aldrich, Milan, Italy) or rabbit IgG was added to the precleared lysates overnight at $4{ }^{\circ} \mathrm{C}$ and the day after, dynabeads were added for $3 \mathrm{~h}$ at $4{ }^{\circ} \mathrm{C}$. After washing, the beads-bound proteins were processed for Western blot or RNA purification and qRT-PCR.

\subsection{Protein Extraction and Western Blotting}

Protein was extracted from CRC cells using RIPA buffer $(50 \mathrm{mM}$ Tris- $\mathrm{HCl} \mathrm{pH} 8$, $150 \mathrm{mM} \mathrm{NaCl}, 1 \% \mathrm{NP}-40,0.5 \%$ sodium deoxycholate, $0.1 \%$ SDS) supplemented with protease inhibitors (Complete Mini, Roche, Monza, Italia) and a cocktail of phosphatase inhibitors ( $5 \mathrm{mM}$ sodium fluoride, $1 \mathrm{mM}$ sodium vanadate and $1 \mathrm{mM}$ PMSF). SDS-PAGE (Bio-rad, Segrate, Italy) was performed as previously described [12]. Antibodies used are listed in Table S2. Densitometric analysis was performed using Image Lab 6.1 software (Biorad Laboratories, Segrate, Italy). 


\subsection{Soft Agar Assay}

The soft agar assay was performed as described elsewhere [33]. Briefly, $2 \times 10^{5}$ Caco-2 cells (control and siRAC1b) were plated in the upper layer and stained after 2 months with p-nitroblue tetrazolium (NBT, Sigma, Milano, Italy) for colony visualization and quantification.

\subsection{Enrichment Analyses}

Analyses have been conducted on $\mathrm{R}$ free software environment for statistical computing and graphics (version 3.6.3). Bioconductor package ClusterProfiler (v3.12.0) has been used for enrichment analysis [34]. We focused on Biological Process, Cellular Component and Molecular Function of Gene Ontology (GO) resource. GO keywords with no more than 2000 associated genes were analyzed and Benjamini-Hochberg (BH) strategy for false discovery rate (FDR) was applied by using a cut-off at 0.05 both for $p$-value and $q$-value.

\subsection{Colorectal Cancer Expression Datasets}

ESRP1, RAC1 and RAC1b expression were analyzed from CRC expression datasets as follows. RAC1 isoforms analysis was performed based on specific isoforms expression data. The data for $R A C 1$ (uc003spx) and $R A C 1 b$ (uc003spw) isoforms were obtained from TCGA COAD dataset as reported at TCGA Synapse group (available online: https: / /www. synapse.org/\#!Synapse:syn300013/tables/ (accessed on 15 July 2021) [35]. Expression data for ESRP1 were taken from Xena Functional Genomics Explorer TCGA COAD gene expression by RNAseq (polyA + IlluminaGA) (https://xenabrowser.net/, accessed on 15 July 2021). We also performed RAC1 isoforms analysis based on percent spliced in (PSI, defined as the ratio between the number of reads supporting exon inclusion and the combined number of reads regarding inclusion and exclusion) values [36]. Ryan et al. analyzed TCGA data and showed how $R A C 1 b$ isoform is expressed in colon tumors (COAD). We have correlated this percentage value with the ESRP1 RNAseq-HTSeq-FPKMUQ expression value (as found in GDC TCGA Colon Cancer (COAD)) [37].

Moreover, in order to highlight possible differences in $R A C 1$ behavior according to ESRP1 expression level in TCGA COAD, samples with low ESPR1 and high ESRP1 expression were selected. Specifically the two groups composed of samples belonging to the first and the fourth quartile, respectively, were considered.

\subsection{Statistical Analyses}

Data in bar graphs are expressed as mean \pm standard deviation. Data in the whisker plot of Figure S1 are expressed as median and first and fourth quartiles. Statistical differences were determined by a 2-tailed Student's t-test $\left({ }^{*} p<0.05,{ }^{* *} p<0.01\right.$, ${ }^{* * *} p<0.001$, $* * * * p<0.0001)$.

\section{Results}

\subsection{Gene Expression Profiling of ESRP1-Modulated COLO320DM and HCA24 Cells}

We previously demonstrated that ESRP1 expression is absent in the highly metastatic cell line COLO320DM, while it is expressed at elevated levels in HCA24 cells [11]. These cells were chosen for the experiments as they do no bear the most common driver mutations of CRC in BRAF, KRAS, PIK3CA and NRAS [19]. COLO320 DM cells are undifferentiated tumorigenic cells that exhibit epithelial to mesenchymal transition (EMT) features as shown by the absence of epithelial markers, such as E-cadherin, EpCAM, cytokeratin, and the presence of mesenchymal markers such as vimentin. Consistently, they have strong metastatic potential in vivo as observed in experimental metastasis models [11,38,39]. On the other hand, HCA24 cells have strong epithelial features and are highly differentiated cells that generate large xenografts in vivo without any evidence of metastasis generation [40]. Thus, we re-introduced ESRP1 cDNA in COLO320DM and silenced the expression of ESRP1 in HCA24 cells. ESRP1-overexpressing COLO320DM cells showed enhanced proliferation in suspension and significantly increased the formation of macro-metastasis in the liver 
with respect to empty controls when delivered through the tail vein. On the other hand, ESRP1-silencing in HCA24 cells abrogated their capacity to proliferate in suspension and to form colonies in soft agar with respect to control cells [11].

In order to investigate in more depth, the mechanism by which ESRP1 regulates anchorage-independent growth and tumorigenesis in CRC cells, we performed high throughput gene expression profiling analysis of ESRP1-modulated COLO320DM and HCA24 cells versus respective controls (Figure 1). The results show that ESRP1 overexpression in COLO320DM cells can induce changes in the expression of transcripts involved in, for example, cell-cell adhesion (biological process), and cell projection and actin cytoskeleton reorganization (cellular component) as evidenced by gene ontology analysis (Figure 1A and Table S3). Changes pertaining to cellular architecture are important drivers of tumorigenesis [41]. On the other hand, ESRP1-silencing in HCA24 cells resulted in differential expression of transcripts involved in, for instance, RNA-binding (molecular function), mRNA metabolism and translation (biological process), and ribosome (cellular component) pertaining to the role of ESRP1 in RNA biogenesis (Figure 1B and Table S4).

The cDNA microarray data were experimentally validated with qRT-PCR analysis in both cell lines. In agreement with the cDNA microarray results, EPB41L5 expression was found to be down-regulated, while RBM35A (ESRP1), ACTA2, FOLR1 and MT1E to be up-regulated upon ESRP1 overexpression in COLO320DM cells with respect to empty controls (Figure 2A and Table S5). On the other hand, NUPR1 expression was found to be down-regulated, while ALDH3A1, SERPINI1, CYP1A1 and CHRNA expression was found to be up-regulated in ESRP1-silenced HCA24 cells compared to the scramble control cells (Figure 2B and Table S6). A small number of genes were found to be commonly differentially expressed in the two cell lines upon ESRP1 modulation, as expected due to their inherent differences (Table S7). Overall, these results suggest that the modulation of ESRP1 expression levels induces gene expression changes in both CRC cell lines.

\subsection{ESRP1 Positively Regulates RAC1b Expression in CRC Cells}

Interestingly, among the most significantly differentially expressed genes (Figure 1), RAC1 topped in COLO320DM cells overexpressing ESRP1. RAC1 was also found in the list of significantly differentially expressed genes in the HCA24 cells silenced for ESRP1 expression. The probe that on the microarray platform identifies the differential expression of $R A C 1$ refers specifically to exon $3 b$, which is part of a particular isoform, $R A C 1 b$, of the $R A C 1$ gene itself (Table S8). The TCGA COAD datasets were further analyzed for correlation between ESRP1 and RAC1 or RAC1b expression. As shown in Figure 3, RAC1b expression, with respect to $R A C 1$, showed statistically significant positive correlation with that of ESRP1 in the CRC patient samples. A further evaluation of $R A C 1 b$-specific exon inclusion, using the percent spliced in (PSI) approach, showed that there is a significant and positive correlation between ESRP1 and PSI values for RAC1 in 452 tumor samples, but not in the corresponding 41 normal samples. There are also indications from TCGA COAD datasets, that low ESRP1 and high ESRP1 subsets of CRC (first and the fourth quartile) show differential expression of $R A C 1$ isoforms and RAC1 PSI (Figure S1). 


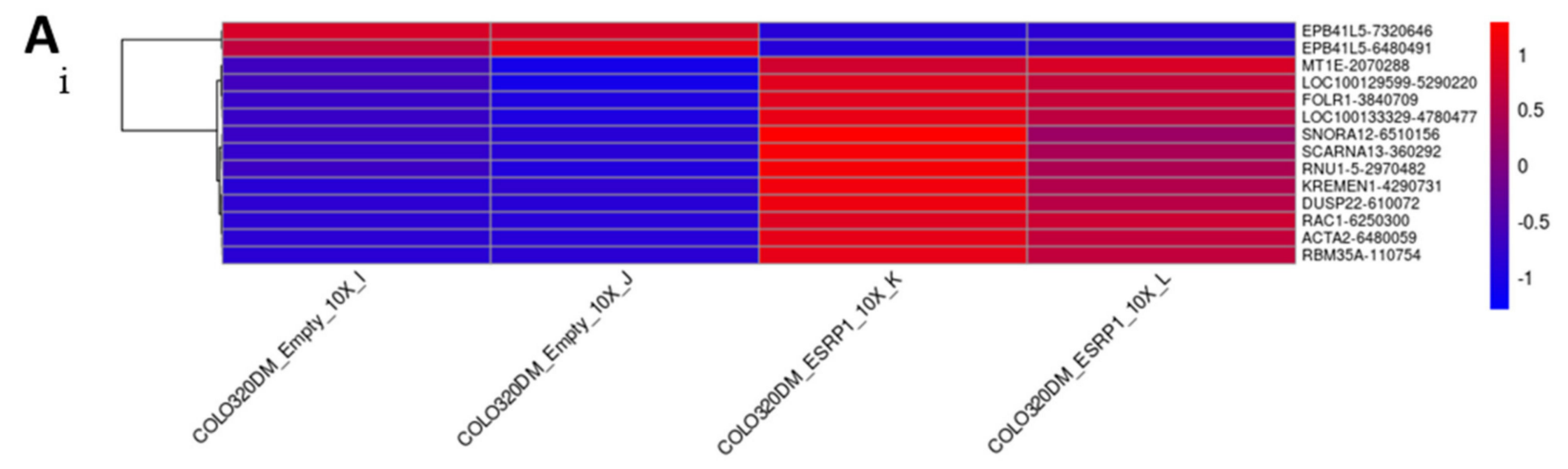

ii

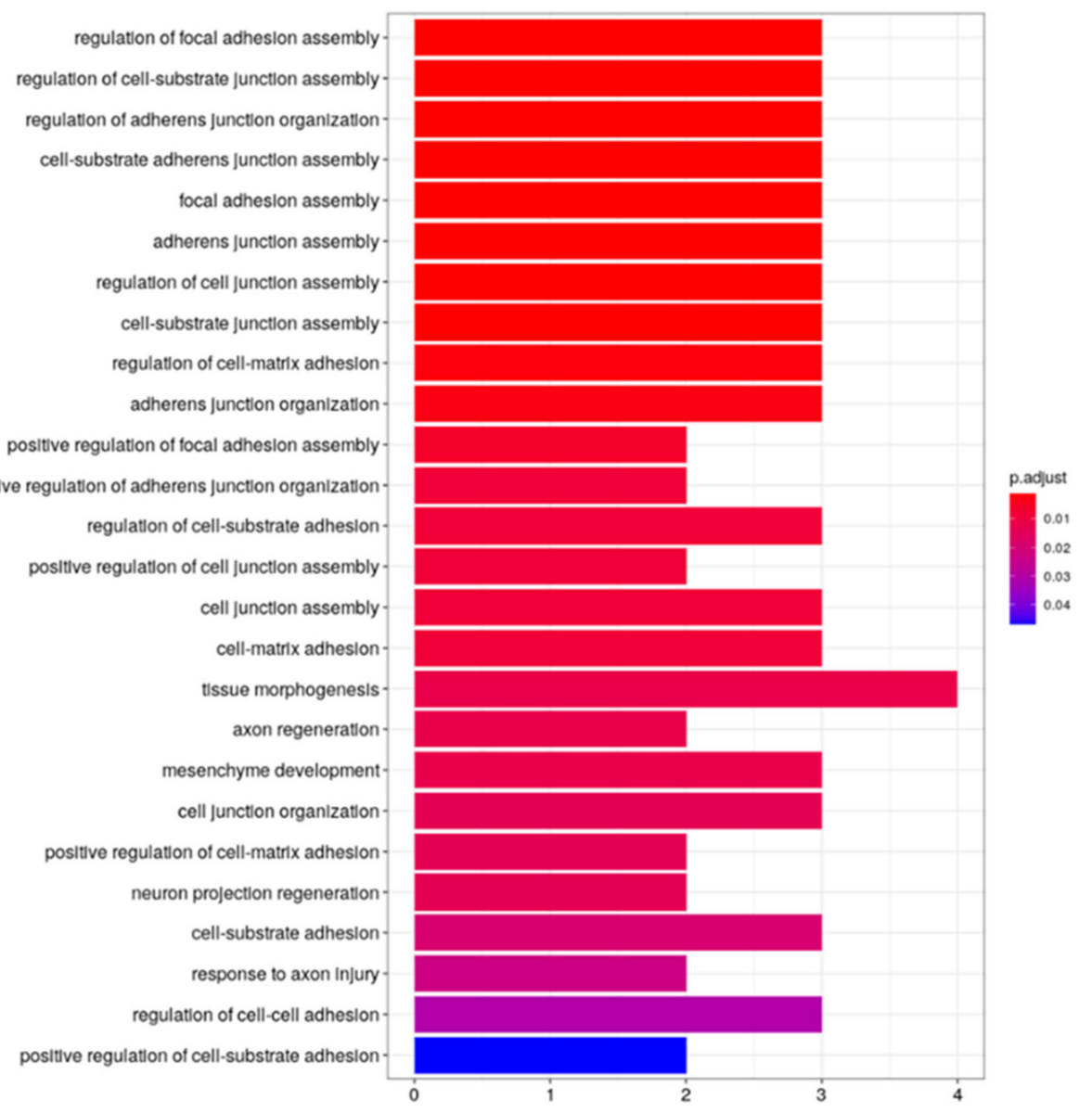

Figure 1. Cont. 


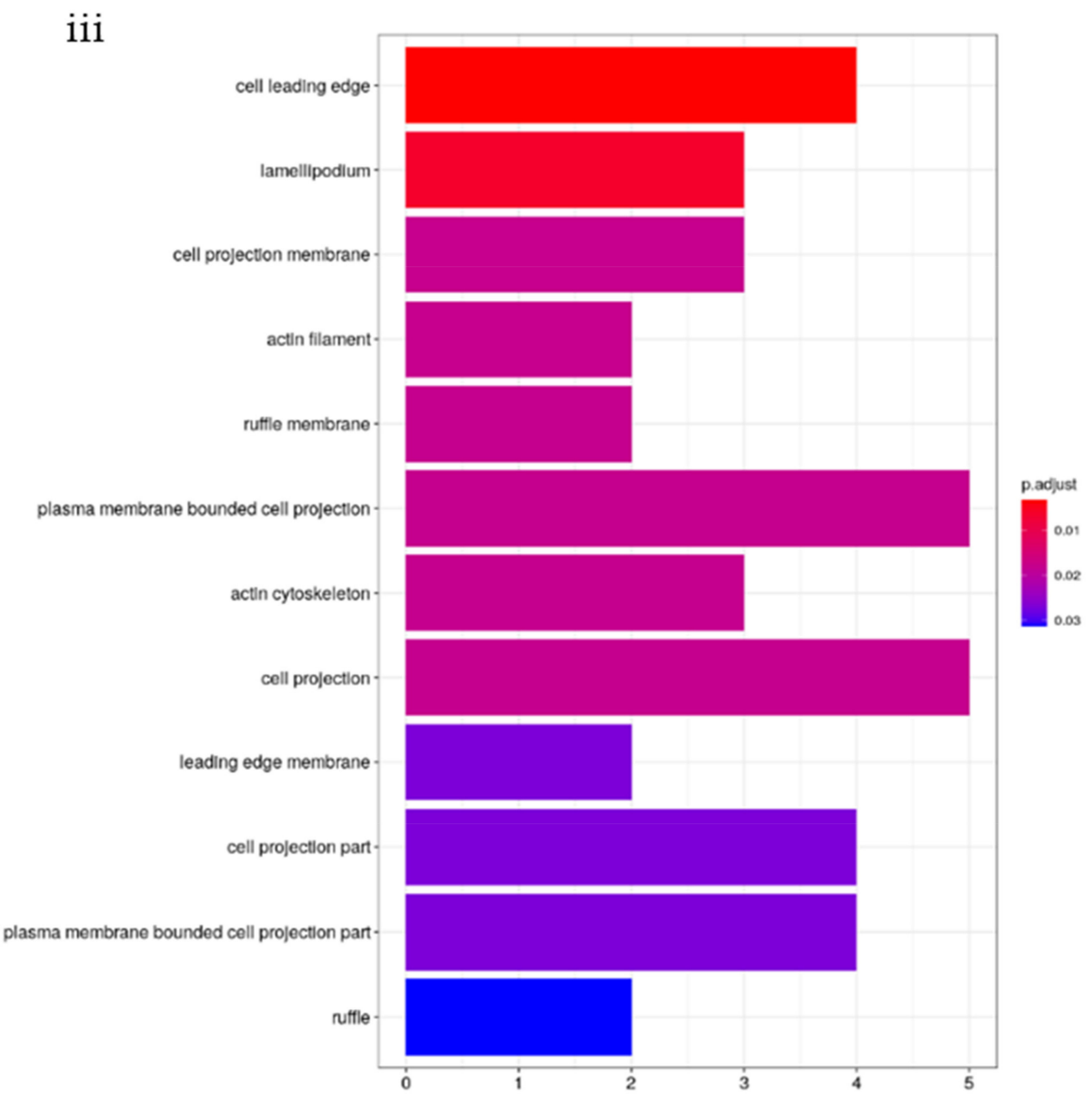

Figure 1. Cont. 


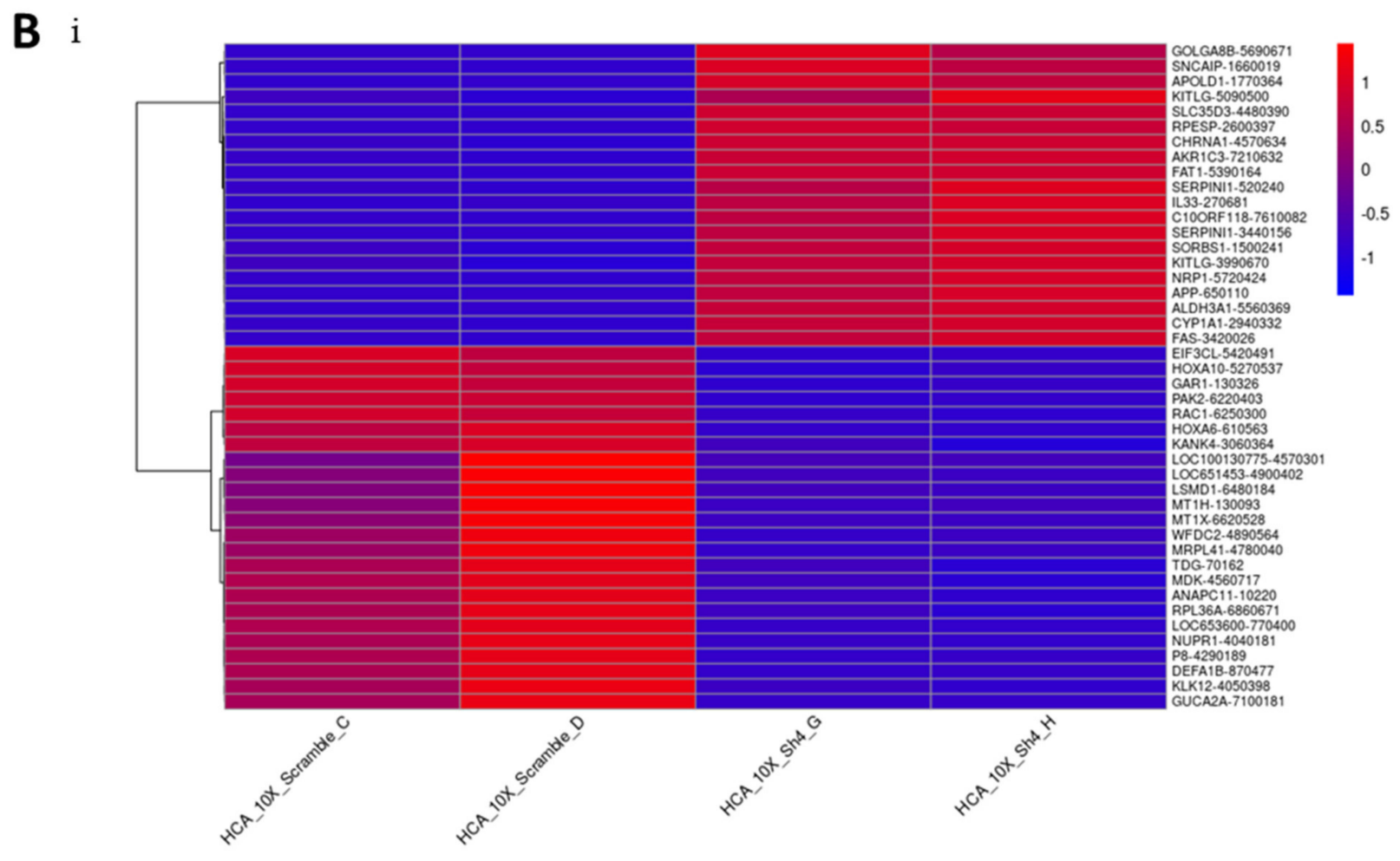

ii

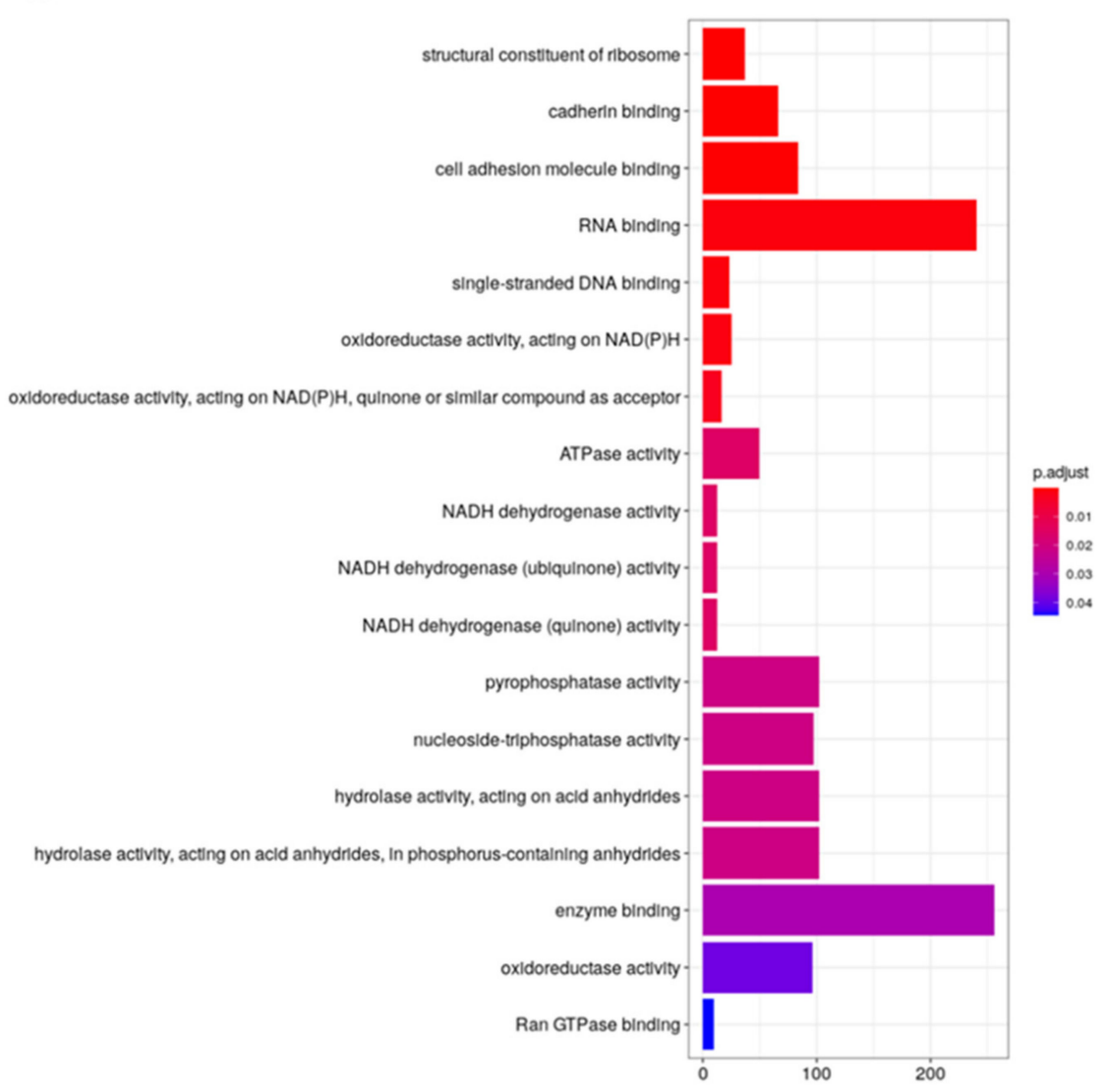

Figure 1. Cont. 


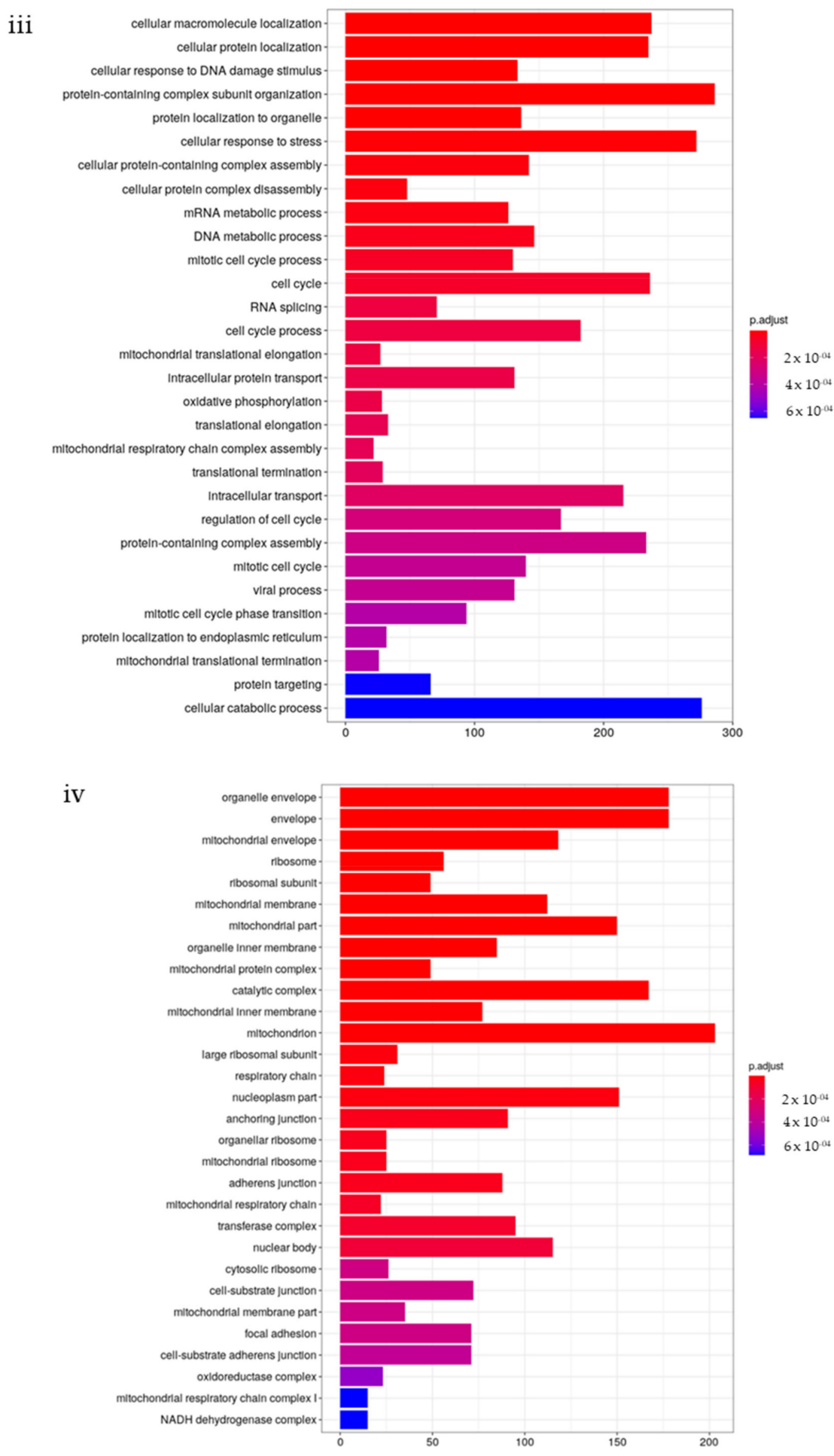

Figure 1. Gene expression profiling of ESRP1-modulated CRC cells. (A). (i) Heatmap of ESRP1-overexpressing and control CO-LO320DM cells. Cells are shown in columns and genes in rows (genes are reported as Gene Name and Illumina Array Address ID). Gene ontology keywords belonging to (ii) biological process domain and (iii) cellular component domain are reported on the $\mathrm{y}$-axis, the number of differentially expressed genes involved in the corresponding GO term enrichment is defined on the x-axis, whereas the different colors highlight the different magnitude of the $p$-values (as in the legend). (B). (i) Heatmap of ESRP1-silenced and control HCA24 cells. Only gene showing a $\mid \log 2 \mathrm{FCl}>1.5$ are considered in this graphical representation. Cells are shown in columns and genes in rows (genes are reported as Gene Name and Illumina Array Address ID). HCA24 enriched Gene Ontology keywords belonging to (ii) molecular function domain, (iii) biological process domain and (iv) cellular component domain are reported on the y-axis, the number of differentially expressed genes involved in the corresponding GO term enrichment is defined on the x-axis, whereas the different colors highlight the different magnitude of the $p$-values (as in the legend). 


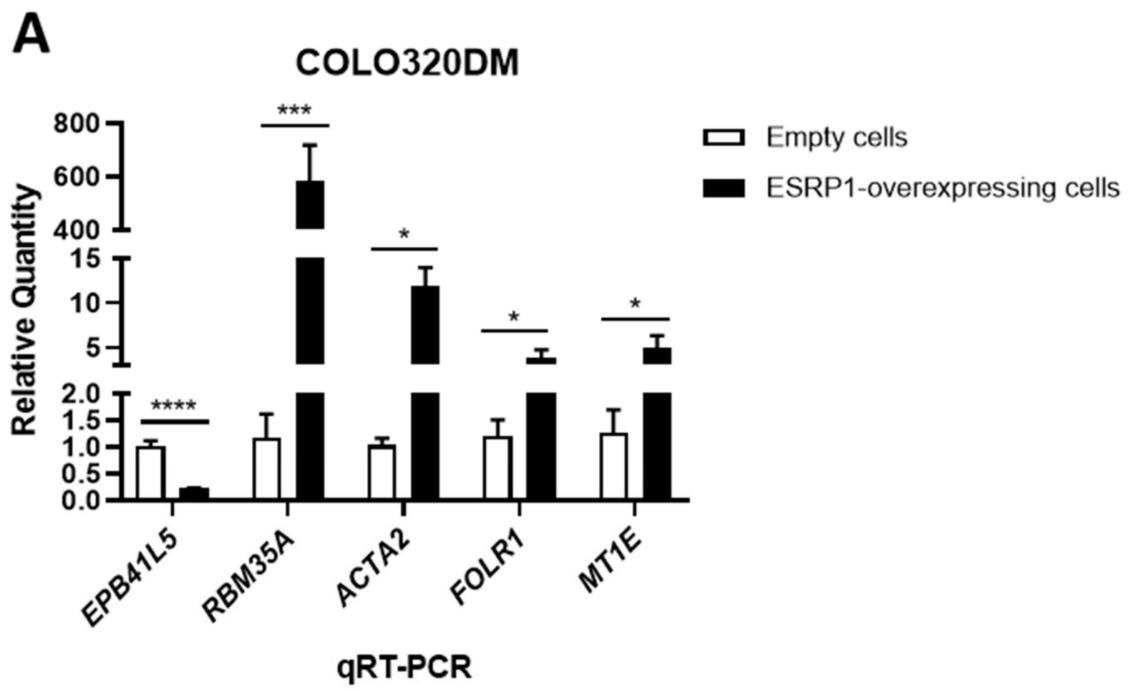

B

\section{HCA24}

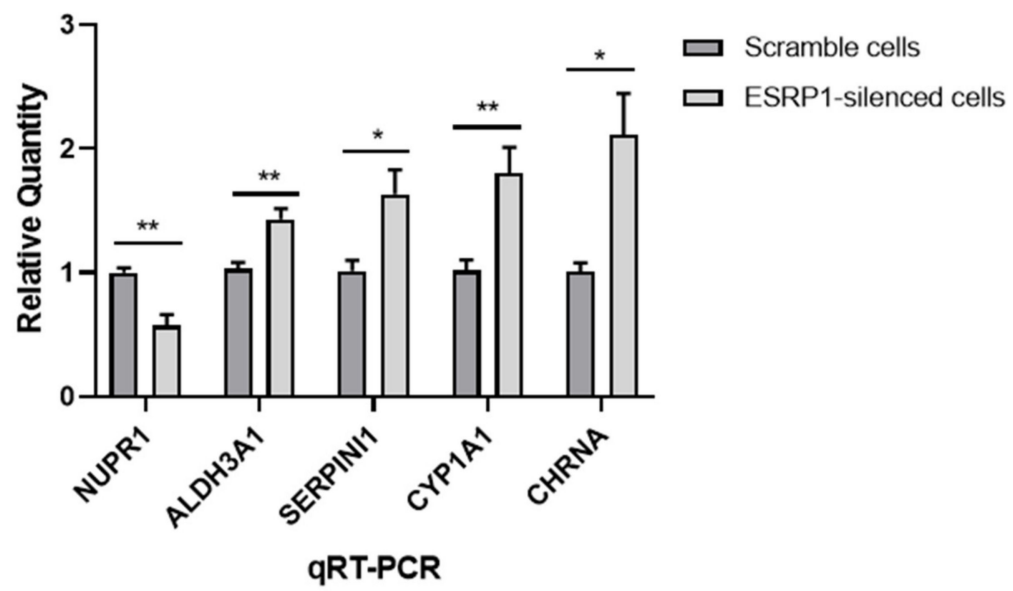

Figure 2. Microarray data validation. (A) Gene expression levels of EPB41L5, RBM35A (ESRP1), ACTA2, FOLR1 and MT1E in ESRP1-modulated COLO320DM cells $(n=6)$. (B) Gene expression levels of NUPR1, ALDH3A1, SERPINI1, CYP1A1 and CHRNA in ESRP1-modulated HCA24 cells $(n=4)$. Data are expressed as mean \pm SEM of relative quantification using the delta-delta Ct method over control (empty and scramble in COLO320DM and HCA24 cells, respectively) cells. Normalization was made using GAPDH as housekeeping gene. Unpaired t-test was performed: ${ }^{*} p<0.05,{ }^{* *} p<0.01$, *** $p<0.001, * * * * * 0.0001$.

We thus focused our attention on RAC1b. RAC1b and ESRP1 showed a similar expression behavior according to the differential expression analysis in both CRC cell lines (Figure 4A,B). CDNA microarray data were validated both at the RNA and protein levels by qRT-PCR and Western blot analyses, respectively, in independent experiments. Consistently, RAC1b was found to be up-regulated and down-regulated in COLO320DM ESRP1-overexpressing and HCA24 ESRP1-silenced cells, respectively, compared to their respective controls (Figure $4 \mathrm{~A}, \mathrm{~B}$ ). On the other hand, RAC1 mRNA expression level was not significantly different among the ESRP1-modulated CRC cells (Figure 4A,B). 
RAC1 isoforms analysis: specific isoforms expression
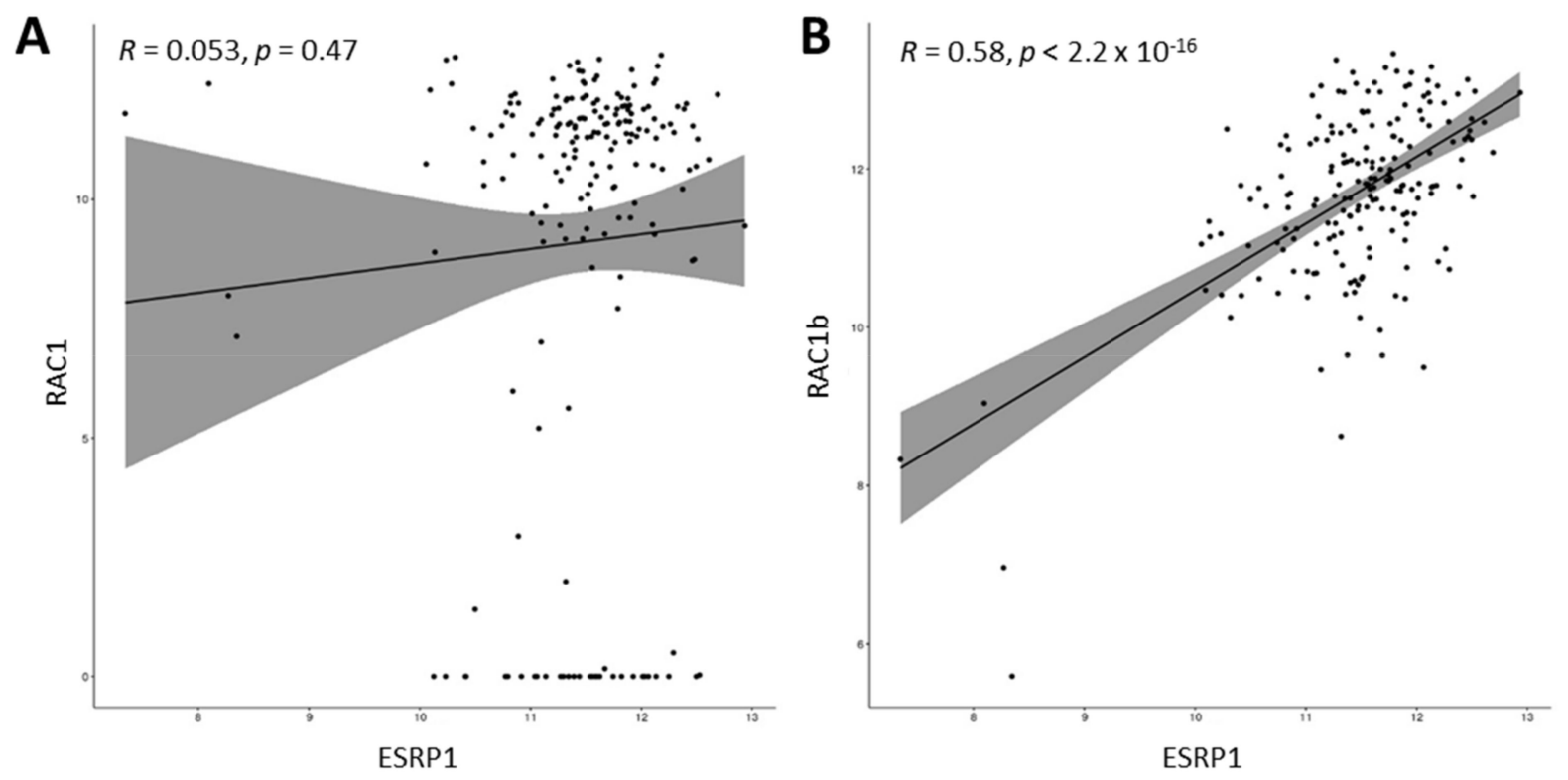

RAC1 isoforms analysis: Percent Spliced In (PSI)
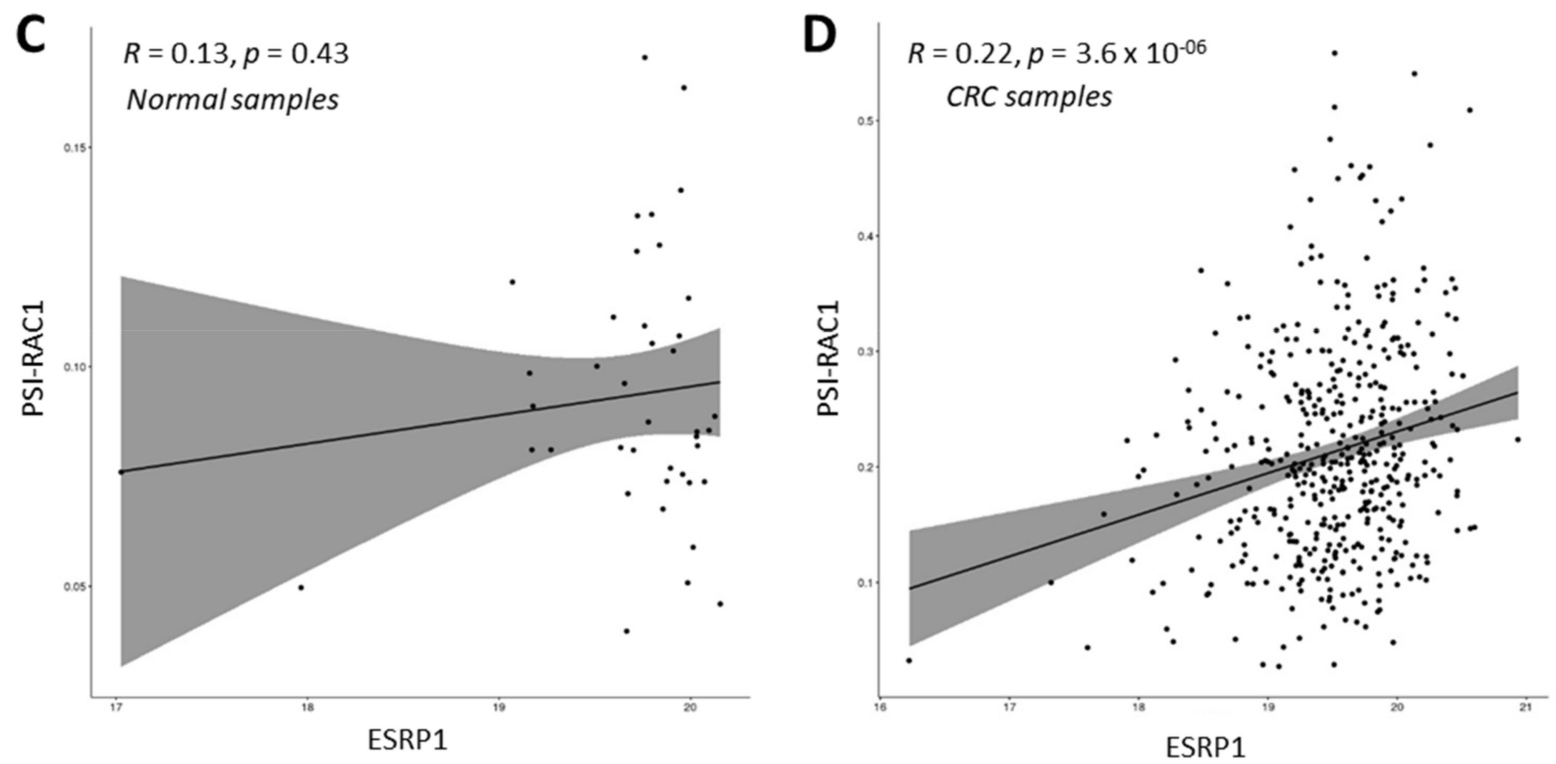

Figure 3. RAC1 isoforms analysis. (A) Pearson correlation analysis between ESRP1 and RAC1 (uc003spx) in TCGA COAD tumor samples. (B) Pearson correlation analysis between ESRP1 and RAC1B (uc003spw) in TCGA COAD tumor samples. This specific isoform shows a positive and statistically significant correlation. (C) Pearson correlation analysis between ESRP1 and PSI values related to RAC1 in TCGA COAD normal samples. (D) Pearson correlation analysis between ESRP1 and PSI values related to RAC1 in TCGA COAD tumor samples. In this specific tumor context, the percent spliced in values related to RAC1 shows a positive and statistically significant correlation. 


\section{A}

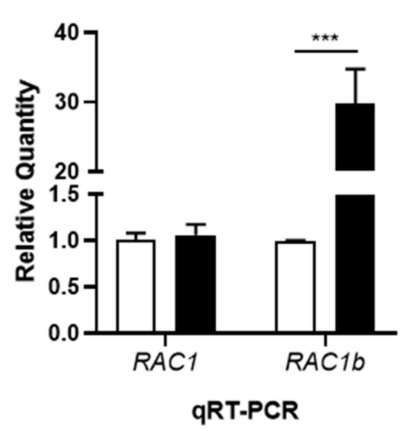

B

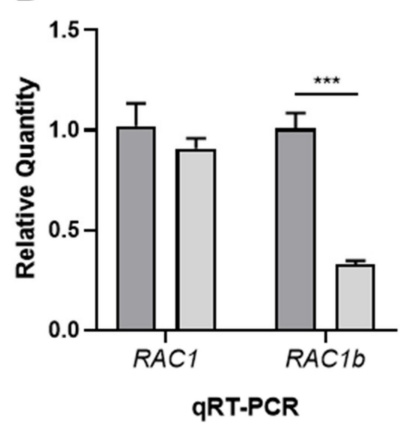

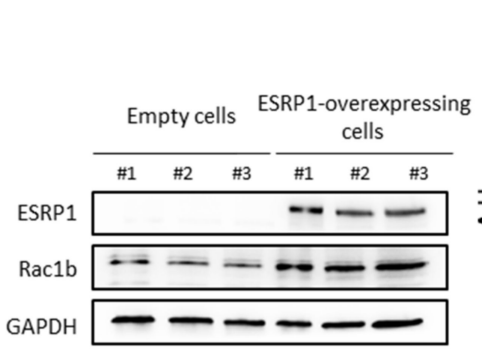

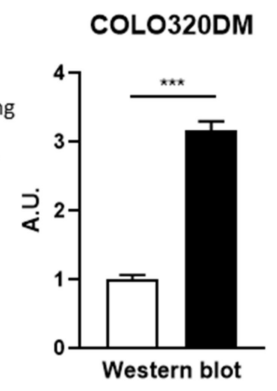

$\square$ Empty cells

- ESRP1-overexpressing cells

C

Caco-2

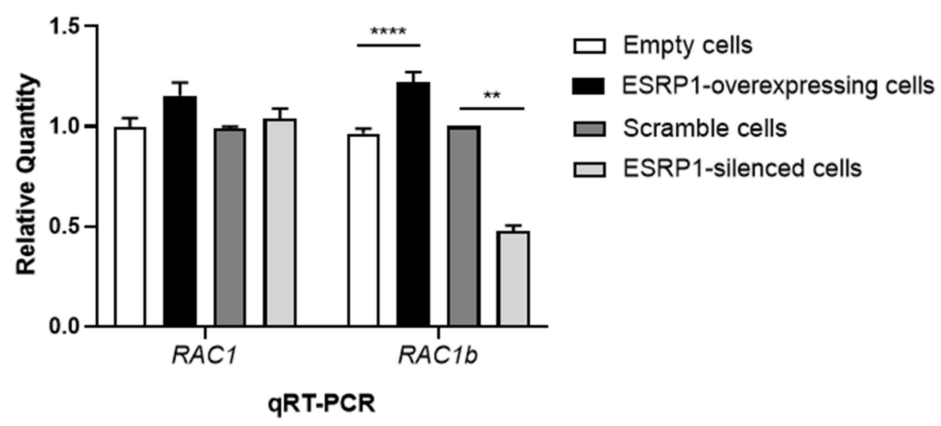

Figure 4. RAC1b data validation in all CRC cell lines under study. (A) RAC1b up-regulation in COLO320DM cells was validated by qRT-PCR (on the left) and Western blot (on the right) analysis ( $n=5$ for qRT-PCR and $n=3$ for Western blot). (B) RAC1b down-regulation in HCA24 cells was validated by qRT-PCR (on the left) and Western blot (on the right) analysis $(n=4)$. (C) RAC1b deregulation upon ESRP1 modulation in Caco-2 cells was validated by qRT-PCR $(n=3)$. RAC1 expression levels were evaluated by qRT-PCR analysis in all CRC cell lines. Data are expressed as mean \pm SEM of relative quantification using the delta-delta Ct method over control (empty and scramble) cells. Normalization was made using GAPDH as housekeeping gene. Unpaired t-test was performed: ${ }^{*} p<0.05,{ }^{* *} p<0.01,{ }^{* * *} p<0.001,{ }^{* * *} p<0.0001$.

In order to analyze if ESRP1 and RAC1b also showed a similar trend in expression in a normal colon-like cell line, we analyzed RAC1b expression in Caco-2 cells, which express intermediate levels of ESRP1 (comparable to the normal colon) and which underwent both ESRP1 overexpression and silencing as previously reported [11]. Interestingly, RAC1b expression increased when ESRP1 was over-expressed in Caco-2 cells, while its expression decreased when ESRP1 expression was silenced (Figure 4C). Of note, RAC1 expression was not significantly different among the ESRP1-modulated Caco-2 cells (Figure 4C).

Overall, these results suggest that RAC1b expression, both at protein and mRNA levels, is positively regulated by ESRP1 in all CRC cells under study. On the contrary, total RAC1 mRNA level did not change, thus allowing us to speculate that ESRP1 can directly lead to a switch from the canonical to the alternatively spliced variant RAC1b. 
3.3. The Expression of Known Regulators of Rac1b Splicing Is Not Affected by ESRP1 Modulation in CRC Cells

Previous studies have reported ASF/SF2 (also known as SFRS1) and SRp20 (also known as SFRS3) as the master splicing regulators of RAC1 [25]. Moreover, it has also been shown that SRPK1 and GSK3 $\beta$ are involved in the regulation of such splicing factors [42]. In order to investigate whether, in our cellular models, these players can somehow be involved in orchestrating RAC1 splicing upon ESRP1 modulation, we interrogated our cDNA microarray data for SFRS1, SFRS3, SRPK1 and GSK3 $\beta$ expression. Of note, there was no statistically significant differences in the datasets analyzed, thus suggesting that other mechanisms might be involved (Table 1).

Table 1. Expression of splicing factors to be directly involved in RAC1b splicing. cDNA microarray data generated on the two ESRP1-modulated cell lines, COLO320DM and HCA24 were analyzed for expression of RAC1b. COLO320 DM, $\log \mathrm{FC}=1.45, p$-Value Adjusted $=0.003 ; \mathrm{HCA} 24, \log \mathrm{FC}=-1.88$, $p$-Value Adjusted $=2.77 \times 10^{-05}$.

\begin{tabular}{ccccc}
\hline CRC Cell Line & Gene & logFC & $p$-Value & $p$-ValueAdj \\
\hline & SFRS1 & -0.489781297 & 0.012866813 & 0.365144154 \\
\cline { 2 - 5 } $\begin{array}{c}\text { COLO320DM } \\
\text { (vs. empty cells) }\end{array}$ & SRPK1 & -0.357614922 & 0.025871261 & 0.42769659 \\
\cline { 2 - 5 } & SFRS3 & -0.450996868 & 0.030901422 & 0.446890088 \\
\cline { 2 - 5 } & SFRS3 & -0.161124083 & 0.293793057 & 0.791369823 \\
\hline & GSK3 $\beta$ & -0.163911091 & 0.288342371 & 0.788788089 \\
\cline { 2 - 5 } & SFRS1 & 0.173660122 & 0.229342737 & 0.587853808 \\
\cline { 2 - 5 } HCA24 & SFRS3 & 0.070938569 & 0.581454363 & 0.844252266 \\
\cline { 2 - 5 } & SFRS3 & -0.034194091 & 0.847903379 & 0.9514723978 \\
\hline
\end{tabular}

\subsection{RAC1 mRNA Co-Immunoprecipitates with ESRP1}

ESRP1 is a well-known splicing factor capable of binding the GU-rich sequence motifs of several mRNAs [43]. Of note, a GU-rich ESRP-binding consensus sequence (UGGUGGGUG) was found 274 bp upstream of exon 3b [18]. Based on our cDNA microarray data, as well as Western blot and qRT-PCR analyses, we speculated whether ESRP1 can directly bind pre-mRNA $R A C 1$, thereby promoting the inclusion of exon $3 \mathrm{~b}$ and generating $\mathrm{RAC} 1 \mathrm{~b}$ isoform at the expense of the canonical one.

To this end, we performed RNA-immunoprecipitation with anti-ESRP1 antibody on ESRP1-overexpressing COLO320DM cells, in which RAC1b was one of the most significantly differentially expressed genes, with respect to empty controls, highlighted by the cDNA microarray data (Figure 1). IgG was used as negative control. Interestingly, qRTPCR analysis of ESRP1-bound transcripts revealed the presence of both $R A C 1$ and $R A C 1 b$ isoform compared to IgG controls (Figure 5). These results suggest that ESRP1 may have a direct role in RAC1 alternative splicing and on RAC1b expression.

\subsection{RAC1b Silencing Affects Anchorage-Independent Tumor Growth in CRC Cells}

We have previously shown that ESRP1-overexpressing Caco-2 cells are capable of generating colonies in soft agar with respect to empty controls [11]. Caco-2 overexpressing cells recapitulated some of the early oncogenic changes, such as enhanced proliferation and growth in anchorage-independency. In order to investigate whether ESRP1 exerts its pro-tumorigenic function through RAC1b, the ESRP1-overexpressing Caco-2 cells were transfected with two siRNAs against RAC1b. Cells were analyzed after $48 \mathrm{~h}$ transfection for the expression of RAC1b. Both siRNAs efficiently down-regulated RAC1b mRNA and protein expression in these cells (Figure 6A,B). Interestingly, RAC1b silencing reduced the 
number of ESRP1-overexpressing Caco-2 cells colonies in soft agar (Figure 6C,D). Overall, these results suggest that ESRP1, by directly regulating the splicing of RAC1 and the expression of RAC1b, is capable of regulating the anchorage-independent growth and tumorigenesis in CRC cells.

A

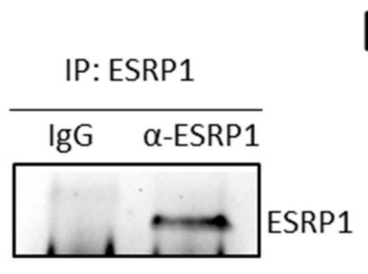

B

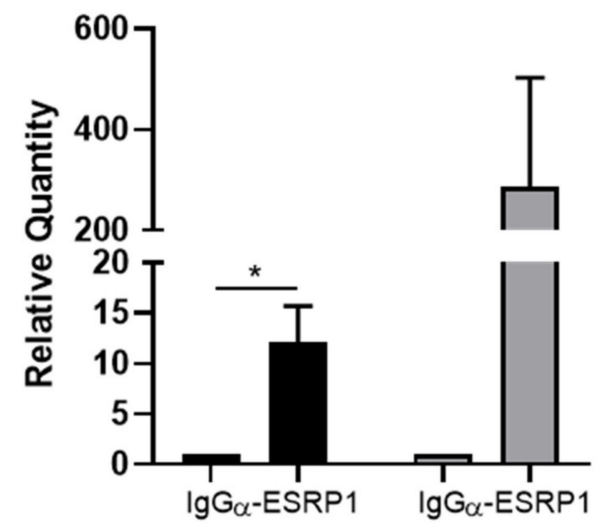

RAC1 口 RAC1b

Figure 5. RNA-immunoprecipitation (RNA-IP) in ERSP1-overexpressing COLO320DM CRC cells. (A) Western blot analysis of ESRP1 immunoprecipitation. Rabbit IgG was used as negative control. (B) qRT-PCR analysis of ESRP1- and IgG-bound transcripts. Gene expression levels of $R A C 1$ and $R A C 1 b$ in three independent experiments of RNA-IP. Data are expressed as mean \pm SEM of quantification relative to IgG negative control. Unpaired t-test was performed: ${ }^{*} p<0.05$.

A

\section{ESRP1-overexpressing Caco-2 cells}

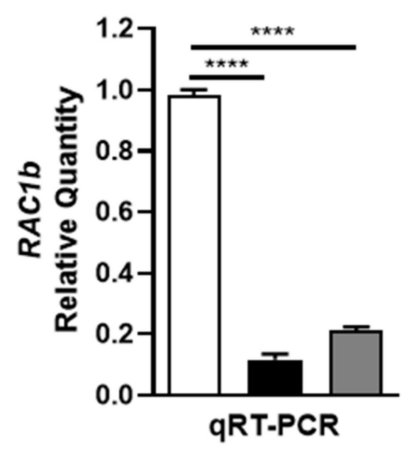

C

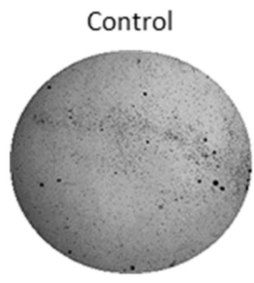

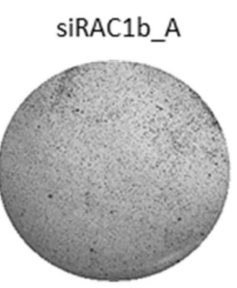

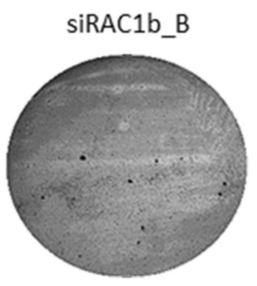

B

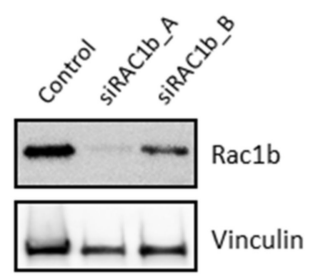

D

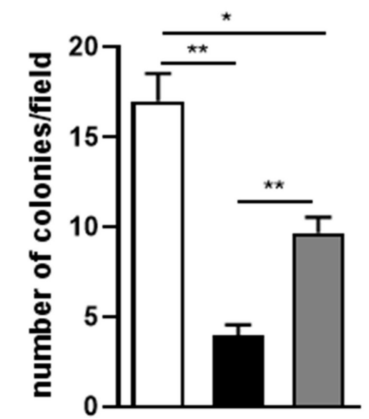

口 Control

- siRAC1b_A

口 siRAC1b_B

Figure 6. RAC1b silencing in ESRP1-overexpressing Caco-2 cells. (A) Gene expression levels of RAC1b in Caco-2 cells $(n=3)$. Data are expressed as mean \pm SEM of relative quantification using the delta-delta Ct method over IgG negative control, and normalized using GAPDH as housekeeping gene. Unpaired t-test was performed: ${ }^{* * *} p<0.0001$. (B) Western blot analysis of RAC1b in Caco-2 cells. (C-D). Soft agar assay. (C) Representative images and (D) quantification of colonies $(n=3)$. Data are expressed as mean \pm SEM. Unpaired t-test was performed: ${ }^{*} p<0.05,{ }^{* *} p<0.01$. 


\section{Discussion}

It has become increasingly clear that posttranscriptional gene regulation strictly regulates every cancer hallmark [44-47]. Indeed, RBPs, by orchestrating mRNA processing and translation, are thought to play a crucial role in tumor development. As an RBP, ESRP1 has been shown to be involved in several cellular processes, such as alternative splicing and regulation of translation, as well as mRNA stability [21,48]. We previously demonstrated that in some CRC cases, ESRP1 is aberrantly overexpressed, and acts as an oncogene [11,12]. In the present study, we further investigated the underlying molecular mechanisms by which ESRP1 exerts its pro-tumorigenic function by performing large-scale gene expression profiling on two different CRC cell lines, in which ESRP1 expression was modulated. Intriguingly, comparison of datasets of our cDNA microarray data revealed that few genes were commonly differentially expressed between the two cells lines (Table S7). This was expected due to the different oncogenic pathways activated in the strongly mesenchymal COLO320DM cells, in which ESRP1 was re-expressed, and the epithelial HCA24 cells, in which ESRP1 expression was silenced. RAC1b was one of the most significantly differentially expressed gene present in both CRC cell lines (i.e., HCA24 and COLO320DM), and was hence selected for further experiments. ESRP1 and RAC1b expression showed similar trend. These results were further confirmed in a third normal colon-like cell line (Caco-2) which was modulated for ESRP1 expression. We provide herein the first evidence that ESRP1 positively regulates the expression level of the alternatively spliced RAC1b isoform. Of note, bioinformatic analysis of TGCA COAD dataset further corroborated our experimental results. No changes in the relative expression of $R A C 1$ mRNA were observed upon ESRP1 modulation. We thus postulate that ESRP1 is capable of regulating $R A C 1$ pre-mRNA splicing, thereby promoting the inclusion of variant exon $3 \mathrm{~b}$ and the generation of RAC1b isoform. An RNA-based regulation of RAC1b may also be possible [49]. Silencing of RAC1b in ESRP1-overexpressing Caco-2 cells partially reverted the oncogenic phenotype of these cells (soft agar assay), thus supporting the fact that ESRP1 exerts its pro-tumorigenic function by acting through RAC1b.

Mammalian $R A C 1$ gene can give rise to two alternative transcripts, the predominant $R A C 1$ and the alternative isoform $R A C 1 b$, which contains an additional 57 nucleotides-long exon $3 \mathrm{~b}$. Importantly, $R A C 1 b$ has been found aberrantly expressed in a subset of CRC tumors [20]. The in-frame insertion of 19 amino acid results in the constitutive activation of this small GTPase [50-52]. Over the years, RAC1b has been recognized as a pro-tumorigenic player, due to its involvement in several key processes including cell cycle progression and apoptosis resistance [53]. Moreover, RAC1b plays a critical role in the development of resistance to cancer therapies. RAC1b may be considered as a predictor of chemotherapy efficacy in metastatic CRC [54,55]. Indeed, Alonso-Espinaco et al. showed that RAC1b is a poor survival marker in KRAS/BRAF wild-type CRC patients treated with first-line FOLFOX/XELOX therapy [54]. Likewise, Goka et al. later demonstrated that CRC cells (i.e., HT116 and HT29) up-regulated RAC1b expression upon chemotherapy treatment, thereby promoting NF- $\mathrm{kB}$ pathway and cell survival gene transcription [55]. The inhibition of RAC1 prevents the activation of these pathways associated to chemotherapy treatment and increases the sensitivity of the cells to oxaliplatin and 5-FU.

Two independent studies have demonstrated so far that ESRP1 negatively regulates RAC1b $[18,56]$. In particular, Ishii et al. showed that the down-modulation of ESRP1 in human head and neck squamous cell carcinoma cell lines (i.e., SAS and HSC4) led to the induction of RAC1b expression [18]. Moreover, Deng et al., demonstrated that the overexpression of ESRP1 inhibited the generation of RAC1b in the ovarian cancer cell line SKOV3 [56]. However, no direct interaction between ESRP1 and RAC1b was shown in these studies. On the other hand, our results clearly show that in three different CRC cell lines, ESRP1 expression correlates with that of RAC1b and that the ESRP1-containing ribonuclear protein complex can bind both $R A C 1$ and $R A C 1 b$ mRNA. Importantly, each alternative splicing event is controlled by multiple RBPs, rather than just a single RBP [57]. Moreover, each cell type expresses a distinct array of RBPs, thus dictating a distinct 
pattern of alternatively splice products. Thus, the cellular context matters and each cell distinguishes itself by the relative abundance of each RBP, which becomes the major determinant of pre-mRNA splicing. Thus, future studies should focus on analyzing the ESRP1-containing complexes to determine which proteins and RNA species are present under a given condition.

The RNA-binding protein ESRP1 is as a key splicing regulator related to EMT [58]. In particular, ESRP1 directs an epithelial splicing program. Specifically, it binds and regulates the splicing of several EMT-related mRNA targets (i.e., FGFR2, CD44, ENAH and CTNND1), and orchestrates the switch to the epithelial-specific transcript variants at the expense of the mesenchymal ones [48,59]. Moreover, it has also been demonstrated that EMT-associated transcription factors (i.e., $\delta E F 1$, SIP1, SNAIL, SLUG and TWIST) downregulate ESRP1 [60-63]. Recently, the alternative splice variant RAC1b has been recognized as the "guardian of the epithelial phenotype", due to its ability to interfere with the TGF- $\beta$ induced cell migration and EMT [64]. Taken together, it may be possible that ESRP1 and RAC1b work in concert to ensure the maintenance of an epithelial phenotype, as pointed out by the analysis of TCGA COAD data on ESRP1 or RAC1b versus representative EMT genes (E-cadherin and Vimentin), as well as to modulate chemoresistance development (Figure S2) [55].

\section{Conclusions}

To our knowledge, this is the first report of ESRP1 exerting its pro-tumorigenic function through RAC1b. ESRP1 is capable of binding RAC1 mRNA, thereby promoting the inclusion of the variant exon $3 b$ and modulating RAC1b expression. Our data solicits further work to address more in depth the molecular mechanisms of ESRP1-induced regulation of RAC1b expression and its biological effect in CRC progression for instance by employing genetically modified mice models.

Supplementary Materials: The following are available online at https: / www.mdpi.com/article / 10.3390 / cancers13164092/s1, Figure S1: Differential expression analysis of RAC1 in TCGA COAD samples, as reported in the Material and Methods section, Figure S2: Pearson correlation coefficient and statistical analysis between representative EMT genes and ESRP1 and RAC1b, respectively, Table S1: Primers and SiRNA sequences used in the present study; Table S2: Antibodies used in the present study; Table S3: Gene ontology analysis of genes differentially expressed in the COLO320DM cells, Table S4: Gene ontology analysis of genes differentially expressed in the HCA24 cells., Table S5: List of differentially expressed genes in the COLO320DM cells, Table S6: List of differentially expressed genes in the HCA24 cells; Table S7: Table with the common genes found differentially expressed in COLO320DM and HCA24 cell lines; Table S8: RAC1 probe information on Illumina cDNA microarray platform.

Author Contributions: Conceptualization, M.M., U.A. and S.F.; methodology, M.M., U.A. and D.C.; validation, M.M.; software, U.A. and E.M.; visualization, D.C. and E.T.; supervision, S.F.; writingoriginal draft preparation, M.M., U.A. and S.F..; writing-review and editing, M.M., U.A., E.M., F.A. and S.F.; funding acquisition, F.A. All authors have read and agreed to the published version of the manuscript.

Funding: The APC was supported by RILO grant (University of Turin) to FA.

Institutional Review Board Statement: Not applicable.

Informed Consent Statement: Not applicable.

Data Availability Statement: Datasets have been deposited in GEO database, with accession numbers GSE180125 and GSE180126.

Conflicts of Interest: The funders had no role in the design of the study; in the collection, analyses, or interpretation of data; in the writing of the manuscript, or in the decision to publish the results. 


\section{References}

1. Sung, H.; Ferlay, J.; Siegel, R.L.; Laversanne, M.; Soerjomataram, I.; Jemal, A.; Bray, F. Global cancer statistics 2020: GLOBOCAN estimates of incidence and mortality worldwide for 36 cancers in 185 countries. CA Cancer J. Clin. 2021, 71, 209-249. [CrossRef]

2. Xie, Y.-H.; Chen, Y.-X.; Fang, J.-Y. Comprehensive review of targeted therapy for colorectal cancer. Signal Transduct. Target. Ther. 2020, 5, 1-30. [CrossRef]

3. Shibue, T.; Weinberg, T.S.R.A. EMT, CSCs, and drug resistance: The mechanistic link and clinical implications. Nat. Rev. Clin. Oncol. 2017, 14, 611-629. [CrossRef] [PubMed]

4. Vu, T.; Datta, P.K. Regulation of EMT in colorectal cancer: A culprit in metastasis. Cancers 2017, 9, 171. [CrossRef]

5. Jung, G.; Hernández-Illán, E.; Moreira, L.; Balaguer, F.; Goel, A. Epigenetics of colorectal cancer: Biomarker and therapeutic potential. Nat. Rev. Gastroenterol. Hepatol. 2020, 17, 111-130. [CrossRef]

6. Yang, Y.; Yan, X.; Li, X.; Ma, Y.; Goel, A. Long non-coding RNAs in colorectal cancer: Novel oncogenic mechanisms and promising clinical applications. Cancer Lett. 2021, 504, 67-80. [CrossRef] [PubMed]

7. Algaber, A.; Al-Haidari, A.; Madhi, R.; Rahman, M.; Syk, I.; Thorlacius, H. MicroRNA-340-5p inhibits colon cancer cell migration via targeting of RhoA. Sci. Rep. 2020, 10, 1-8. [CrossRef]

8. Zhu, J.; Xu, Y.; Liu, S.; Qiao, L.; Sun, J.; Zhao, Q. MicroRNAs associated with colon cancer: New potential prognostic markers and targets for therapy. Front. Bioeng. Biotechnol. 2020, 8. [CrossRef]

9. Fan, X.; Liu, L.; Shi, Y.; Guo, F.; Wang, H.; Zhao, X.; Zhong, D.; Li, G. Integrated analysis of RNA-binding proteins in human colorectal cancer. World J. Surg. Oncol. 2020, 18, 1-14. [CrossRef]

10. Kang, D.; Lee, Y.; Lee, J.-S. RNA-binding proteins in cancer: Functional and therapeutic perspectives. Cancers 2020, 12, 2699. [CrossRef]

11. Fagoonee, S.; Picco, G.; Orso, F.; Arrigoni, A.; Longo, D.L.; Forni, M.; Scarfò, I.; Cassenti, A.; Piva, R.; Cassoni, P.; et al. The RNA-binding protein ESRP1 promotes human colorectal cancer progression. Oncotarget 2016, 8, 10007-10024. [CrossRef] [PubMed]

12. Ala, U.; Manco, M.; Mandili, G.; Tolosano, E.; Novelli, F.; Provero, P.; Altruda, F.; Fagoonee, S. Proteomics-based evidence for a pro-oncogenic role of ESRP1 in human colorectal cancer cells. Int. J. Mol. Sci. 2020, 21, 575. [CrossRef]

13. Yae, T.; Tsuchihashi, K.; Ishimoto, T.; Motohara, T.; Yoshikawa, M.; Yoshida, G.; Wada, T.; Masuko, T.; Mogushi, K.; Tanaka, H.; et al. Alternative splicing of CD44 mRNA by ESRP1 enhances lung colonization of metastatic cancer cell. Nat. Commun. 2012, 3, 883. [CrossRef]

14. Jeong, H.M.; Han, J.; Lee, S.H.; Park, H.-J.; Lee, H.J.; Choi, J.-S.; Lee, Y.M.; Choi, Y.-L.; Shin, Y.K.; Kwon, M.J. ESRP1 is overexpressed in ovarian cancer and promotes switching from mesenchymal to epithelial phenotype in ovarian cancer cells. Oncogenesis 2017, 6, e389. [CrossRef]

15. Leontieva, O.V.; Ionov, Y. RNA-binding motif protein 35A is a novel tumor suppressor for colorectal cancer. Cell Cycle 2009, 8 , 490-497. [CrossRef]

16. Yao, J.; Caballero, O.L.; Huang, Y.; Lin, C.; Rimoldi, D.; Behren, A.; Cebon, J.; Hung, M.-C.; Weinstein, J.N.; Strausberg, R.L.; et al. Altered expression and splicing of ESRP1 in malignant melanoma correlates with epithelial-mesenchymal status and tumor-associated immune cytolytic activity. Cancer Immunol. Res. 2016, 4, 552-561. [CrossRef]

17. Lee, H.H.; Lee, A.J.; Park, W.S.; Lee, J.; Park, J.; Park, B.; Joung, J.Y.; Lee, K.H.; Hong, D.; Kim, S.H. Epithelial splicing regulatory protein (ESPR1) expression in an unfavorable prognostic factor in prostate cancer patients. Front. Oncol. 2020, 10, 556650. [CrossRef] [PubMed]

18. Ishii, H.; Saitoh, M.; Sakamoto, K.; Kondo, T.; Katoh, R.; Tanaka, S.; Motizuki, M.; Masuyama, K.; Miyazawa, K. Epithelial splicing regulatory proteins 1 (ESRP1) and 2 (ESRP2) suppress cancer cell motility via different mechanisms. J. Biol. Chem. 2014, 289, 27386-27399. [CrossRef] [PubMed]

19. Medico, E.; Russo, M.; Picco, G.; Cancelliere, C.; Valtorta, E.; Corti, G.; Buscarino, M.; Isella, C.; Lamba, S.E.; Martinoglio, B.; et al. The molecular landscape of colorectal cancer cell lines unveils clinically actionable kinase targets. Nat. Commun. 2015, 6, 7002. [CrossRef] [PubMed]

20. Matos, P.; Oliveira, C.; Velho, S.; Gonçalves, V.; Da Costa, L.T.; Moyer, M.P.; Seruca, R.; Jordan, P. B-RafV600E cooperates with alternative spliced Rac1b to sustain colorectal cancer cell survival. Gastroenterology 2008, 135, 899-906. [CrossRef] [PubMed]

21. Fagoonee, S.; Bearzi, C.; di Cunto, F.; Clohessy, J.; Rizzi, R.; Reschke, M.; Tolosano, E.; Provero, P.; Pandolfi, P.P.; Silengo, L.; et al. The RNA binding protein ESRP1 fine-tunes the expression of pluripotency-related factors in mouse embryonic stem cells. PLoS ONE 2013, 8, e72300. [CrossRef]

22. Wang, X.; Jin, H.; Jiang, S.; Xu, Y. MicroRNA-495 inhibits the high glucose-induced inflammation, differentiation and extracellular matrix accumulation of cardiac fibroblasts through downregulation of NOD1. Cell. Mol. Biol. Lett. 2018, 23, 1-13. [CrossRef]

23. Duong, H.-Q.; You, K.S.; Oh, S.; Kwak, S.-J.; Seong, Y.-S. Silencing of NRF2 reduces the expression of ALDH1A1 and ALDH3A1 and sensitizes to 5-FU in pancreatic cancer cells. Antioxidants 2017, 6, 52. [CrossRef] [PubMed]

24. Divi, R.L.; Lindeman, T.L.E.; Shockley, M.E.; Keshava, C.; Weston, A.; Poirier, M.C. Correlation between CYP1A1 transcript, protein level, enzyme activity and DNA adduct formation in normal human mammary epithelial cell strains exposed to benzo[a]pyrene. Mutagenesis 2014, 29, 409-417. [CrossRef]

25. Gonçalves, V.; Matos, P.; Jordan, P. Antagonistic SR proteins regulate alternative splicing of tumor-related Rac1b downstream of the PI3-kinase and Wnt pathways. Hum. Mol. Genet. 2009, 18, 3696-3707. [CrossRef] 
26. Xu, X.; Li, S.; Lin, Y.; Chen, H.; Hu, Z.; Mao, Y.; Xu, X.; Wu, J.; Zhu, Y.; Zheng, X.; et al. MicroRNA-124-3p inhibits cell migration and invasion in bladder cancer cells by targeting ROCK1. J. Transl. Med. 2013, 11, 276. [CrossRef] [PubMed]

27. Jia, L.; Li, J.; Li, P.; Liu, D.; Li, J.; Shen, J.; Zhu, B.; Ma, C.; Zhao, T.; Lan, R.; et al. Site-specific glycoproteomic analysis revealing increased core-fucosylation on FOLR1 enhances folate uptake capacity of HCC cells to promote EMT. Theranostics 2021, 11, 6905-6921. [CrossRef]

28. Yu, J.; Zhu, H.; Li, R.; Jiang, Q.; Luan, W.; Shi, J.; Liu, P. Oncogenic role of NUPR1 in ovarian cancer. OncoTargets Ther. 2020, 13, 12289-12300. [CrossRef] [PubMed]

29. Matsuda, Y.; Miura, K.; Yamane, J.; Shima, H.; Fujibuchi, W.; Ishida, K.; Fujishima, F.; Ohnuma, S.; Sasaki, H.; Nagao, M.; et al. SERPINI1 regulates epithelial-mesenchymal transition in an orthotopic implantation model of colorectal cancer. Cancer Sci. 2016, 107, 619-628. [CrossRef]

30. Lam, D.C.-L.; Girard, L.; Ramirez, R.D.; Chau, W.-S.; Suen, W.-S.; Sheridan, S.; Tin, V.P.; Chung, L.-P.; Wong, M.P.; Shay, J.W.; et al. Expression of nicotinic acetylcholine receptor subunit genes in non-small-cell lung cancer reveals differences between smokers and nonsmokers. Cancer Res. 2007, 67, 4638-4647. [CrossRef]

31. Masiulionytė, B.; Valiulytè, I.; Tamašauskas, A.; Skiriutė, D. Metallothionein genes are highly expressed in malignant astrocytoma and associated with patient survival. Sci. Rep. 2019, 9, 5406. [CrossRef]

32. Ritchie, M.; Phipson, B.; Wu, D.; Hu, Y.; Law, C.W.; Shi, W.; Smyth, G.K. Limma powers differential expression analyses for RNA-sequencing and microarray studies. Nucleic Acids Res. 2015, 43, e47. [CrossRef] [PubMed]

33. Liu, P.; Begley, M.J.; Michowski, W.; Inuzuka, H.; Ginzberg, M.; Gao, D.; Tsou, P.; Gan, W.; Papa, A.; Kim, B.M.; et al. Cell-cycleregulated activation of Akt kinase by phosphorylation at its carboxyl terminus. Nat. Cell Biol. 2014, 508, 541-545. [CrossRef]

34. Yu, G.; Wang, L.-G.; Han, Y.; He, Q.-Y. ClusterProfiler: An R package for comparing biological themes among gene clusters. OMICS J. Integr. Biol. 2012, 16, 284-287. [CrossRef] [PubMed]

35. Gudiño, V.; Pohl, S.-G.; Billard, C.V.; Cammareri, P.; Bolado, A.; Aitken, S.; Stevenson, D.; Hall, A.E.; Agostino, M.; Cassidy, J.; et al. RAC1B modulates intestinal tumourigenesis via modulation of WNT and EGFR signalling pathways. Nat. Commun. 2021, 12, 1-17. [CrossRef]

36. Pervouchine, D.D.; Knowles, D.G.; Guigó, R. Intron-centric estimation of alternative splicing from RNA-seq data. Bioinformatics 2012, 29, 273-274. [CrossRef] [PubMed]

37. Ryan, M.; Wong, W.C.; Brown, R.; Akbani, R.; Su, X.; Broom, B.; Melott, J.; Weinstein, J. TCGASpliceSeq a compendium of alternative mRNA splicing in cancer. Nucleic Acids Res. 2015, 44, D1018-D1022. [CrossRef]

38. Tommelein, J.; Gremonprez, F.; Verset, L.; De Vlieghere, E.; Wagemans, G.; Gespach, C.; Boterberg, T.; Demetter, P.; Ceelen, W.; Bracke, M.; et al. Age and cellular context influence rectal prolapse formation in mice with caecal wall colorectal cancer xenografts. Oncotarget 2016, 7, 75603-75615. [CrossRef] [PubMed]

39. Hamada, K.; Monnai, M.; Kawai, K.; Nishime, C.; Kito, C.; Miyazaki, N.; Ohnishi, Y.; Nakamura, M.; Suemizu, H. Liver metastasis models of colon cancer for evaluation of drug efficacy using NOD/Shi-scid IL2Rgammanull (NOG) mice. Int. J. Oncol. $2008,32$.

40. Kirkland, S.C.; Bailey, I.G. Establishment and characterisation of six human colorectal adenocarcinoma cell lines. Br. J. Cancer 1986, 53, 779-785. [CrossRef]

41. Aseervatham, J. Cytoskeletal remodeling in cancer. Biology 2020, 9, 385. [CrossRef]

42. Gonçalves, V.; Henriques, A.A.; Pereira, J.F.D.S.; Costa, A.N.; Moyer, M.P.; Moita, L.; Carvalho, M.D.G.; Matos, P.; Jordan, P. Phosphorylation of SRSF1 by SRPK1 regulates alternative splicing of tumor related Rac1b in colorectal cells. RNA 2014, 20, 474-482. [CrossRef]

43. Harvey, S.E.; Xu, Y.; Lin, X.; Gao, X.; Qiu, Y.; Ahn, J.; Xiao, X.; Cheng, C. Coregulation of alternative splicing by hnRNPM and ESRP1 during EMT. RNA 2018, 24, 1326-1338. [CrossRef] [PubMed]

44. Kim, M.-Y.; Hur, J.; Jeong, S.-J. Emerging roles of RNA and RNA-binding protein network in cancer cells. BMB Rep. 2009, 42, 125-130. [CrossRef]

45. Silvera, D.; Formenti, S.C.; Schneider, R. Translational control in cancer. Nat. Rev. Cancer 2010, 10, 254-266. [CrossRef] [PubMed]

46. Abdelmohsen, K.; Gorospe, M. Posttranscriptional regulation of cancer traits by HuR. Wiley Interdiscip. Rev. RNA 2010, 1, 214-229. [CrossRef]

47. Bielli, P.; Busà, R.; Paronetto, M.P.; Sette, C. The RNA-binding protein Sam68 is a multifunctional player in human cancer. Endocr Relat. Cancer 2011, 18, R91-R102. [CrossRef] [PubMed]

48. Warzecha, C.; Sato, T.K.; Nabet, B.; Hogenesch, J.B.; Carstens, R.P. ESRP1 and ESRP2 are epithelial cell-type-specific regulators of FGFR2 splicing. Mol. Cell 2009, 33, 591-601. [CrossRef]

49. Xiao, R.; Chen, J.-Y.; Liang, Z.; Luo, D.; Chen, G.; Lu, Z.J.; Chen, Y.; Zhou, B.; Li, H.; Du, X.; et al. Pervasive chromatin-RNA binding protein interactions enable RNA-Based regulation of transcription. Cell 2019, 178, 107-121. [CrossRef]

50. Jordan, P.; Braza, R.; Boavida, M.G.; Gespach, C.; Chastre, E. Cloning of a novel human Rac1b splice variant with increased expression in colorectal tumors. Oncogene 1999, 18, 6835-6839. [CrossRef]

51. Schnelzer, A.; Prechtel, D.; Knaus, U.; Dehne, K.; Gerhard, M.; Graeff, H.; Harbeck, N.; Schmitt, M.; Lengyel, E. Rac1 in human breast cancer: Overexpression, mutation analysis, and characterization of a new isoform, Rac1b. Oncogene 2000, 19, 3013-3020. [CrossRef]

52. Haeusler, L.C.; Hemsath, L.; Fiegen, D.; Blumenstein, L.; Herbrand, U.; Stege, P.; Dvorský, R.; Ahmadian, M.R. Purification and biochemical properties of Rac1, 2, 3 and the splice variant Rac1b. Methods Enzymol. 2006, 406, 1-11. [CrossRef] [PubMed] 
53. Melzer, C.; Hass, R.; Lehnert, H.; Ungefroren, H. RAC1B: A Rho GTPase with versatile functions in malignant transformation and tumor progression. Cells 2019, 8, 21. [CrossRef]

54. Alonso-Espinaco, V.; Cuatrecasas, M.; Alonso, V.; Escudero, P.; Marmol, M.; Horndler, C.; Ortego, J.; Gallego, R.; Codony-Servat, J.; Garcia-Albeniz, X.; et al. RAC1b overexpression correlates with poor prognosis in KRAS/BRAF WT metastatic colorectal cancer patients treated with first line FOLFOX/XELOX chemotherapy. Eur. J. Cancer 2014, 50, 1973-1981. [CrossRef] [PubMed]

55. Goka, E.T.; Chaturvedi, P.; Lopez, D.T.M.; De La Garza, A.; Lippman, M.E. RAC1b overexpression confers resistance to chemotherapy treatment in colorectal cancer. Mol. Cancer Ther. 2019, 18, 957-968. [CrossRef]

56. Deng, G.; Zhou, X.; Chen, L.; Yao, Y.; Li, J.; Zhang, Y.; Luo, C.; Sun, L.; Tang, J. High expression of ESRP1 regulated by circ-0005585 promotes cell colonization in ovarian cancer. Cancer Cell Int. 2020, 20, 1-15. [CrossRef]

57. Fu, X.-D.; Ares, M. Context-dependent control of alternative splicing by RNA-binding proteins. Nat. Rev. Genet. 2014, 15, 689-701. [CrossRef] [PubMed]

58. Shapiro, I.M.; Cheng, A.; Flytzanis, N.C.; Balsamo, M.; Condeelis, J.S.; Oktay, M.H.; Burge, C.B.; Gertler, F.B. An EMT-driven alternative splicing program occurs in human breast cancer and modulates cellular phenotype. PLoS Genet. 2011, 7, e1002218. [CrossRef] [PubMed]

59. Bebee, T.W.; Park, J.W.; Sheridan, K.I.; Warzecha, C.; Cieply, B.W.; Rohacek, A.; Xing, Y.; Carstens, R.P. The splicing regulators Esrp1 and Esrp2 direct an epithelial splicing program essential for mammalian development. eLife 2015, 4, e08954. [CrossRef]

60. Horiguchi, K.; Sakamoto, K.M.; Koinuma, D.; Semba, K.; Inoue, A.; Inoue, S.; Fujii, H.; Yamaguchi, A.; Miyazawa, K.; Miyazono, K.; et al. TGF- $\beta$ drives epithelial-mesenchymal transition through $\delta$ EF1-mediated downregulation of ESRP. Oncogene 2011, 31, 3190-3201. [CrossRef]

61. Li, L.; Qi, L.; Qu, T.; Liu, C.; Cao, L.; Huang, Q.; Song, W.; Yang, L.; Qi, H.; Wang, Y.; et al. Epithelial splicing regulatory protein 1 inhibits the invasion and metastasis of lung adenocarcinoma. Am. J. Pathol. 2018, 188, 1882-1894. [CrossRef] [PubMed]

62. Gemmill, R.M.; Roche, J.; Potiron, V.A.; Nasarre, P.; Mitas, M.; Coldren, C.D.; Helfrich, B.A.; Garrett-Mayer, E.; Bunn, P.A.; Drabkin, H.A. ZEB1-responsive genes in non-small cell lung cancer. Cancer Lett. 2011, 300, 66-78. [CrossRef] [PubMed]

63. Reinke, L.M.; Xu, Y.; Cheng, C. Snail represses the splicing regulator epithelial splicing regulatory protein 1 to promote epithelialmesenchymal transition. J. Biol. Chem. 2012, 287, 36435-36442. [CrossRef] [PubMed]

64. Zinn, R.; Otterbein, H.; Lehnert, H.; Ungefroren, H. RAC1B: A guardian of the epithelial phenotype and protector against epithelial-mesenchymal transition. Cells 2019, 8, 1569. [CrossRef] [PubMed] 